* Doutoranda em Direito Público Internacional pela Pontifícia Universidade Católica de Minas Gerais (PUC-MG). Mestre em Direito Internacional pela Université Paris II, com o título revalidado pela Universidade de Brasília (UnB). Professora do Centro Universitário UNA, do Centro Universitário de Belo Horizonte (UNIBH), da Faculdade PROMOVE de Minas Gerais e da PósGraduação do Centro de Direito Internacional (CEDIN). E-mail: fernandakallas@ hotmail.com

** Doutor em Direito pela Universidade Federal de Minas Gerais (UFMG). Professor da mesma instituição e da Pontifícia Universidade Católica de Minas Gerais (PUC-MG).

\section{A REESTRUTURAÇÃO DA DÍVIDA PÚBLICA ARGENTINA FACE AO DIREITO DE IMUNIDADE DO ESTADO ESTRANGEIRO}

\author{
SOVEREING IMMUNITIES AND ARGENTINA'S \\ DEBT RESTRUCTURING PROCESS
}

\author{
*Fernanda Araújo Kallás e Caetano \\ ** Bruno Wanderley Júnior
}

Resumo: O presente artigo analisa a questão das imunidades de jurisdição e de execução do Estado argentino em solo estrangeiro à luz das recentes decisões dos tribunais norteamericanos sobre a reestruturação da dívida pública argentina contraída durante a crise de 2001. Apesar da maioria dos credores terem concordado com a proposta de negociação, uma minoria composta por fundos especulativos que não aceitou negociar a dívida interpôs uma ação nos Estados Unidos visando obter o pagamento integral do débito. A questão que se coloca é a de saber até que ponto o Estado argentino poderia ser acionado em solo estrangeiro, além de averiguar quais seriam as condições para que se processasse a eventual execução de uma sentença condenatória fora do território da Argentina.

Palavras-chave: Imunidade de jurisdição. Imunidade de execução. Estado estrangeiro. Renúncia à imunidade.

Abstract: This paper aims to an analyze and discuss Argentina's jurisdiction and execution immunities in light of recent rulings made by the United States' courts regarding the South American country's debt restructuring process. Although most creditors agreed to the renegotiated terms, a minority of bondholders, comprised mostly of speculative funds, sought and won an injunction prohibiting Argentina from paying the renegotiated bonds unless they simultaneously paid their holdouts the full amount due. Finally, we ask if and to what extent Argentina can be prosecuted in a foreign land and therefore, we will also examine the necessary conditions for the application of the injunction beyond the Latin American country's territory.

Keywords: Jurisdictional immunity. Immunity from execution. Foreign State, Immunity resignation.

Como citar: CAETANO, Fernanda Araújo Kallás e; WANDERLEY JÚNIOR, Bruno. A reestruturação da dívida 
pública argentina face ao direito de imunidade do estado estrangeiro. Scientia Iuris, Londrina, v. 20, n. 1, p. 42-58, abr. 2016. DOI: $10.5433 / 2178-8189.2016 v 20 n 1 p 42$. ISSN: 2178-8189. 


\section{INTRODUÇÃO}

Em 2001, a Argentina viveu uma crise social, econômica e política que fez com que o Estado caísse em insolvência. Passados alguns anos, o país foi capaz de negociar uma redução do valor de sua dívida com a maioria dos credores. Assim como em um processo de falência, o país renegociou um reembolso de trinta a cinquenta por cento do valor nominal. Como a maioria dos detentores dos títulos da dívida pública concordaram com a proposta, parecia que o problema da Argentina estava resolvido. Ocorre que, os detentores que não aceitaram a negociação venderam suas ações com um enorme desconto para fundos especulativos norte-americanos - que ficaram conhecidos como "fundos abutres"- especializados em comprar títulos à beira da moratória e esperar pacietemente pelo pagamento. Tais fundos travaram uma batalha legal que perdurou por anos, até que em 11 de maio de $2006^{1}$, o Tribunal Federal de Nova Iorque decidiu que seus titulares - dentre eles a Sociedade NML, sedidada nas Ilhas Caiman e os fundos Elliot e Aurelius Capital Managementdeveriam ser reembolsados em cem por cento do valor da dívida. Após terem sido apresentados uma série de recursos por parte da Argentina, a Corte Suprema dos Estados Unidos julgou definitivamente a questão em 16 de junho de 2014², confirmando a decisão do tribunal inferior, que havia entendido que a Argentina, além de ter como obrigação o pagamento do valor integral da dívida, deveria arcar também com os juros e multas devidos.

A decisão final da Corte Suprema norte-americana confirmou a curiosa interpretação dada pelo juiz de primeira instância Griesa à cláusula pari passu, que é uma cláusula que impõe a obrigação de assegurar tratamento igual a todos os credores. Tal cláusula foi interpretada no sentido de que a falta de pagamento dos credores que não aceitaram a renegociação impediria o pagamento regular de mais de noventa por cento dos credores que entraram em acordo com a Argentina. Diante disso, qualquer banco americano que venha a ajudar o Estado argentino a pagar os detentores dos bônus da dívida reestruturada violará uma ordem judicial norte-americana. Essa interpretação foi estratégica porque ela teve o condão de forçar o Estado Argentino a cumprir imeditamente a sentença para não cair em descrédito com os demais credores.

Até que fosse proferida a decisão final, não houve qualquer congelamento

1 Tribunal Federal de Nova York. NML v. Republic of Argentina, No 05 Civ 2434, 2006 WL 1294853. Decisão de 10 de maio de 2006. Disponível em: www.gpo.gov/uscourst/.

2 Suprema Corte dos Estados Unidos. Republic of Argentina v. NML Capital. Sentença de 16 de junho de 2014. Disponível em: http://www.scotusblog.com/case-files/cases/republic-of-argentina-v-nml-capital/. 
ou execução de bens pela justiça estadunidense, já que em 2006, os tribunais norte-americanos indeferiram o pedido de penhora dos bens do Estado argentino detidos no Federal Reserve Bank de Nova Iorque para o pagamento dos valores devidos. $\mathrm{O}$ argumento utilizado foi que o Estado argentino gozava da prerrogativa de imunidade de execução de seus bens no território dos Estados Unidos. Em busca de uma garantia de execução de tais sentenças, as sociedades credoras requereram a penhora dos bens argentinos situados no Reino Unido e na França.

O grande mérito da interpretação feita pelos tribunais norte americanos da cláusula pari passu é que ela livra os fundos credores de uma possível decisão favorável à imunidade de execução dos bens do Estado argentino seja nos Estados Unidos, seja nos demais Estados onde existam bens. Contudo, diante da posição da Argentina de não pagar os fundos abutres até 31 de dezembro de 2014 - data em que a cláusula deixou de vigorar - para continuar o pagamento dos credores que renegociaram a dívida, o problema da imunidade voltou a rondar a questão.

Assim sendo, o presente artigo trata de analisar as duas imunidades do Estado argentino que estão em jogo no presente caso: a imunidade de jurisdição e a imunidade de execução. Ambas serão tratadas nos pontos que se seguem, à luz da doutrina e do entendimento atual dos tribunais tanto internos quanto internacionais.

\section{A IMUNIDADE DE JURISDIÇÃO DO ESTADO ARGENTINO DIANTE DOS TRIBUNAIS ESTADUNIDENSES}

As recentes decisões dos tribunais norte-americanos concernentes aos títulos da dívida pública argentina motivaram o Estado devedor a postular uma demanda na Corte Internacional de Justiça contra os Estados Unidos, que chegou a conhecimento da Corte em 7 de agosto de $2014^{3}$, sob o argumento de que ao permitir o julgamento da Argentina em seus tribunais internos, os Estados Unidos teriam violado a soberania e o direito à imunidade do Estado argentino. Vale, contudo, lembrar que o litígio só poderia ser processado na Corte Internacional de Justiça se os Estados Unidos voluntariamente tivessem manifestado a sua concordância com a jurisdição da Corte, o que não aconteceu.

Diante da impossibilidade de julgamento da questão pela Corte

${ }^{3}$ Corte Internacional de Justiça. Comunicado de imprensa n²014/25. Disponível em: http://www.icj-cij. org/presscom/files/5/18355.pdf. 
Internacional de Justiça, arriscaremos a indicar qual deveria ter sido a correta solução da questão à luz do direito internacional vigente.

Começaremos nossa reflexão, analisando o direito à imunidade de jurisdição do Estado estrangeiro, levando em consideração os limites já consolidados pelo direito internacional atual, uma vez que o princípio da imunidade passou por um sério movimento de relativização no século passado.

As razões que motivaram o desejo de relativização da imunidade de jurisdição dos Estados estrangeiros tiveram relação com o crescente intervencionismo do Estado nas atividades empresariais. Pela lógica do Estado liberal, o comércio, por ser visto como uma atividade inerente à iniciativa privada, quando exercido pelo Estado, desvia a finalidade da imunidade soberana, não merecendo, por isso, ser alcançada por ela (MADRUGA FILHO, 2003, p. 268).

A Bélgica foi pioneira na mudança do conceito de imunidade absoluta que depois se espalharia pelo mundo, quando em 1903 sua Corte de Cassação reconheceu a teoria da imunidade relativa (VERHOEVEN, 2000, p. 736-737). A tese da relativização da imunidade ganhou gradativamente novos adeptos, firmando-se definitivamente nos anos setenta com a celebração da Convenção Europeia sobre a Imunidade dos Estados em 16 de maio de 1972. Algumas legislações internas como o Foreign Sovereign Immunities Act (1976) norteamericano, o State Immunity Act (1978) britânico, o State Immunity Act (1982) do Canadá, e outras de países como a Austrália, Paquistão, Singapura e África do Sul também seguiram o mesmo percurso restritivo no que concerne as imunidades estatais (BROWNLIE, 2008, p. 349). Além disso, a jurisprudência dos mais diversos países rapidamente vinculou-se à ideia de uma imunidade relativa, que resguarda apenas os atos soberanos do Estado do julgamento em uma jurisdição estrangeira.

A base do raciocínio relativista é a seguinte: se é a soberania que justifica a imunidade, por que esta deveria ser garantida quando aquela não estivesse em questão? Sob essa perspectiva, o movimento de relativização não tratou de restringir a imunidade, nem tampouco de criar exceções a ela, mas apenas de conceder ao instituto um alcance condizente com sua razão de ser (VERHOVEN, 2004, p. 5).

Pode-se perceber, assim, que os contratos de financiamento bancário e a emissão de títulos da dívida pública, por terem um caráter naturalmente comercial, não são alcançados pela imunidade de jurisdição sob a perspectiva do atual direito internacional consuetudinário (MADRUGA FILHO, 2003, p. 282). Diante disso, os tribunais norte-americanos não violaram o direito internacional 
ao proceder o julgamento das demandas relacionadas ao pagamento das dívidas da Argentina. Resta, no entanto, saber se a conclusão será a mesma para o que concerne uma possível execução dos bens do Estado Argentino em solo norte-americano. Antes, contudo, analisaremos a imunidade argentina perante a jurisdição arbitral.

\section{A IMUNIDADE DE JURISDIÇÃO DO ESTADO ARGENTINO DIANTE DA ARBITRAGEM DO ICSID}

Parte dos detentores dos títulos da dívida argentina encontrou no ICSID uma via alternativa para postulação de suas demandas. O Centro Internacional de Resolução de Disputas sobre Investimento (ICSID, em inglês) é um órgão ligado ao Banco Mundial criado pela Convenção de Washington de 1965 que tem como função a administração dos procedimentos de conciliação e arbitragem previstos na referida Convenção (SHIBATA, 2009). As arbitragens em questão são comumente processadas entre investidores de um lado e Estados do outro, permitindo assim o acesso direto dos particulares a um mecanismo internacional de solução de controvérsias contra o Estado estrangeiro. Este, por sua vez, filiando-se à solução arbitral do referido centro, renuncia às suas prerrogativas jurisdicionais.

Em agosto de 2011, o tribunal de arbitragem do ICSID se declarou competente para julgar uma lide entre Argentina e cerca de 60.000 investidores italianos ${ }^{4}$, que argumentaram que a falta de pagamento do valor integral da dívida era uma violação do Tratado Bilateral de Investimento (TBI) ratificado entre a Itália e a Argentina. O rol de proteção desse tipo de tratado é bem amplo, assegurando uma série de garantias ao investidor estrangeiro, dentre elas: o direito a um tratamento não menos favorável do que aquele concedido aos investidores provenientes de outros países. A competência para o julgamento foi baseada em uma cláusula compromissória geral prevista no tratado, por meio da qual, ambos os Estados admitiram, antecipadamente, a solução arbitral do ICSID, para todos os contratos que viessem a ser celebrados por eles com investidores da nacionalidade do outro Estado parte.

A decisão sobre a competência foi, contudo, amplamente criticada, uma vez que o artigo $8^{\circ}$ do tratado bilateral em questão dispunha que os investidores deveriam primeiramente ter buscado as vias de recurso interno nos tribunais argentinos, para que, somente depois de dezoito meses, estivessem aptos a

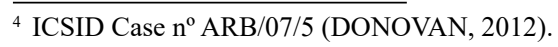


postular uma demanda frente ao ICSID, o que não ocorreu.

George Abi-Saab, um dos três árbitros que atuaram no caso, apresentou sua opinião dissidente frente à decisão sobre a preliminar. Para ele, os títulos da dívida argentina não são investimentos protegidos pelo tratado bilateral de investimentos, uma vez que eles não têm nenhum vínculo territorial com a Argentina. Além disso, segundo o seu entendimento, o consentimento da Argentina à arbitragem do ICSID não alcança ações coletivas como a ação em questão. Sob essa ótica, o tribunal do ICSID teria se atribuído um poder legislativo, modificando substancialmente as regras de procedimento visando atender os anseios desta ação coletiva.

Apesar das críticas, a decisão preliminar foi mantida e o processo encontra-se atualmente na fase de análise do mérito. No entanto, ainda que a sentença proferida pelo tribunal seja favorável aos credores, a execução do Estado argentino não é imediata, uma vez que ela depende de um processo de execução perante os tribunais internos do Estado. Além disso, caso a demanda venha a ser postulada em um Estado estrangeiro com o objetivo de executar os bens do Estado devedor ali situados, o regulamento de arbitragem do ICSID reserva aos Estados condenados o direito de arguir a sua imunidade de execução (GAILLARD, 2003).

Dessa forma, no item seguinte, analisaremos o impacto da imunidade de execução do Estado argentino no pagamento dos valores sentenciados pelos tribunais judiciais estrangeiros e pelos tribunais arbitrais internacionais.

\section{A IMUNIDADE DE EXECUÇÃO DOS BENS DO ESTADO ARGENTINO LOCALIZADOS EM ESTADOS ESTRANGEIROS}

Foi em função da negativa da justiça norte-americana, em 2006, de penhorar os bens do Estado argentino que se encontravam em seu território que os credores resolveram buscar uma forma de garantir a execução da sentença em outros Estados estrangeiros, tais como a França e o Reino Unido. O posicionamento de cada um desses Estados foi diverso no que concerne a

\footnotetext{
Boaventura Santos (2002) a chama de democracia de baixa intensidade.

3 Existem inúmeras diferenças entre o contexto das sociedades europeias, nas quais a teoria de Habermas está baseada e as sociedades em desenvolvimento como a brasileira. No entanto a aplicabilidade de sua teoria em nosso contexto decorre do fato de que a sociedade brasileira é moderna e diferenciada, sendo necessário apenas realizar algumas mediações. Este artigo procura fazer exatamente isso ao trabalhar a capacidade da sociedade civil brasileira de modificar, ainda que em parte, o rumo das decisões institucionais. Uma questão central para o diagnóstico presente neste artigo é precisamente a ideia de que nossas instituições
} 
análise do alcance da imunidade de execução, conforme veremos a seguir.

\subsection{A análise dos tribunais franceses acerca da imunidade de execução do Estado argentino}

É certo que em razão de seu caráter mais atentatório à soberania dos Estados, a renúncia à imunidade de execução deva satisfazer condições formais mais exigentes do que a renúncia à imunidade de jurisdição. Já em 1991, a Comissão de Direito Internacional havia entendido que:

A general waiver or a waiver in respect of all property in the territory of the State of the forum, without mention of any of the specific categories, would not be sufficient to allow measures of constraint against property in the categories listed in paragraph $1 .{ }^{5}$

A jurisprudência dos tribunais franceses caminhou nesse sentido, buscando solidificar exigências mais rigorosas para que os bens de um Estado estrangeiro pudessem vir a ser executados na França.

Podemos exemplificar esse percurso começando pela análise do caso Noga $^{6}$, julgado pela Corte de Apelação de Paris em 10 de agosto de 2000. A demanda era relacionada à uma convenção de arbitragem que a União Soviética - representada no caso pela Federação da Rússia - havia concluído com a sociedade Noga, por ocasião de alguns empréstimos. Nessa convenção, ficou estipulado que todos os litígios que se fizessem presentes entre as partes viriam a ser submetidos à arbitragem da Câmara de Comércio de Estocolmo. A Federação Russa havia renunciado a todo direito de imunidade relativo à aplicação da sentença arbitral que viesse a ser proferida, além de ter expressamente se comprometido a não se privilegiar de nenhuma imunidade processual que pudesse impedir uma eventual execução forçada e apreensão de seus bens.

Ocorre que quando um tribunal arbitral condenou a Rússia ao pagamento de vinte e sete milhões de dólares, a sociedade Noga, buscando o exequatur

\footnotetext{
5 "Uma renúncia geral ou uma renúncia em relação a todos os bens situados no território do Estado do foro, sem menção às categorias específicas de bens, não é suficiente para permitir qualquer medida de coação contra os bens listados nas categorias indicadas no parágrafo 1". (tradução nossa) International Law Commission, Report of the Commission to the General Assembly on the work of its forty-third session, A/CN.4/SER.A/1991/Add.1 (Part 2). Disponível em: http://www.un.org/en/ga/sixth/65/UNCITRAL.shtml.

${ }^{6}$ Corte de Apelação de Paris. Compagnie Noga d'importation et d'exportation v. Embassy of the Russian Federation, No [XP100800X] [2001] D 2157. Decisão de 10 de agosto de 2000.
} 
da sentença na França, requereu a penhora das contas bancárias da Embaixada da Rússia naquele país. A Corte de Apelação, entretanto, entendeu que as disposições acordadas pelas partes não manifestavam a vontade inequívoca do Estado demandado de renunciar a sua imunidade diplomática de execução e permitir que a sociedade demandante viesse a entravar o funcionamento das suas embaixadas e representações no exterior. Para a Corte, diante da especificidade dos bens em questão, seria necessária uma menção expressa e direcionada para que eles não fossem gravados de imunidade.

Entendimento parecido foi novamente esboçado pela Corte de Apelação no mês seguinte por ocasião da sentença do caso République du Cameroun c. Sté Winslow Bank \& Trust. Os contratos de empréstimo realizados a favor do Estado do Cameron continham uma cláusula que dispunha que o mutuário consentia com a execução de qualquer um de seus bens, independente de sua finalidade. A Corte, mais uma vez, entendeu que apesar do contrato conter o consentimento do Estado à sua execução forçada, presume-se que tal execução não possa ser direcionada à propriedade e aos bens das representações diplomáticas do Estado ou àqueles cuja utilização está prevista para tais missões. Ela acrescenta:

la clause usuelle des contrats internationaux de prêt selon laquelle $\mathrm{l}^{\prime}$ Etat accepte de renoncer à l'immunité d'exécution en ce qui concerne l'ensemble de ces biens ou quelle que soit leur destination ne constitue pas une renonciation à l'immunité d'exécution" [...] elle ne désigne pas expressément les biens utilisés par les missions diplomatiques de la République du Cameroun, n'implique pas un consentement de cet Etat à $l^{\prime}$ exécution forcée sur ces catégories de biens. ${ }^{7}$

Tal decisão, que foi posteriormente confirmada pela Corte de Cassação ${ }^{8}$ , mostra-se tão restritiva que parece deslocar para o credor o ônus da prova de que os bens penhorados não são destinados ao funcionamento da representação diplomática.

Já na ação interposta na França pela Sociedade NML contra a Argentina, a Corte de Cassação francesa foi ainda mais criteriosa no intuito de garantir uma proteção da imunidade soberana do Estado. O pedido de execução foi,

\footnotetext{
7 “A cláusula usual dos contratos internacionais de empréstimo, segundo a qual o Estado aceita renunciar a imunidade de execução no que concerne o conjunto de seus bens, qualquer que seja sua destinação, não constitui uma renúncia à imunidade de execução" [...] pois ela "não designa expressamente os bens utilizados pelas missões diplomáticas da República do Cameron, não implicando, desta forma, um consentimento deste Estado à execução forçada sobre tais categorias de bens." (tradução nossa).
} 
nesse caso, direcionado aos ativos não-diplomáticos do Estado, quais sejam, reivindicações de royalties de petróleo, contribuições sociais e impostos devidos por empresas francesas - tais como a Total Austral, Air France e BNP Paribas - para a Argentina através de suas filiais locais. A Corte de Cassação francesa, tratando da questão pela primeira vez, entendeu nas três decisões que proferiu sobre a questão ${ }^{9}$ que esses ativos eram destinados para fins públicos sendo, portanto, imunes à execução, visto que a Argentina não tinha renunciado à sua imunidade soberana. Reiterando a jurisprudência anterior, a Corte ressaltou que a renúncia à imunidade de execução tinha que ser expressa e específica ao mencionar os ativos ou a categoria de bens sobre os quais a isenção é concedida. Não tendo sido o caso, a imunidade de execução do Estado argentino foi julgada procedente.

Os artigos 18 e 19 da Convenção das Nações Unidas sobre Imunidades dos Estados e de seus bens, dispõem nesse sentido. Vejamos:

Art. 18. Não poderão ser tomadas, em conexão com um processo judicial num tribunal de outro Estado, quaisquer medidas cautelares prévias ao julgamento contra os bens de um Estado, tais como o arrolamento ou arresto, salvo se e na medida em que:

a) O Estado consentiu expressamente na aplicação de tais medidas:

i) Por acordo internacional;

ii) Por acordo de arbitragem ou por contrato escrito; ou

iii) Por declaração num tribunal ou por comunicação escrita após o litígio entre as partes ter surgido; ou

b) O Estado reservou ou afectou bens para satisfação do pedido que constitui o objecto desse processo.

Art.19 Não poderão ser tomadas, em conexão com um processo judicial num tribunal de outro Estado, quaisquer medidas de execução posteriores ao julgamento contra os bens de um Estado, tais como o arrolamento, arresto ou penhora,

8 Vide Corte de Cassação Francesa. Primeira Câmara Civil. Republic of Cameroon v. Winslow Bank \& Trust cases. $N^{\circ}$ 04-15.388. Decisão de 14 de Novembro de 2007 in Revue Critique de Droit International Privé, 2008/2, comentário de Mathias Audit.

9 Corte de Cassação Francesa. Primeira Câmara Civil. Sté NML Capital Ltd v. République d'Argentine et Air France, No 11-13-323. Decisão de 28 de março de 2013; Corte de Cassação Francesa. Primeira Câmara Civil. Sté NML Capital Ltd v. République d'Argentine et Total Austral, No 10-25938. Decisão de 28 de março de 2013; Corte de Cassação Francesa. Primeira Câmara Civil. Société NML Capital Ltd v. République Argentine, ${ }^{\circ}$ 09-72.057. Decisão de 28 de Setembro de 2011. 
salvo se e na medida em que:

a) O Estado consentiu expressamente na aplicação de tais medidas:

i) Por acordo internacional;

ii) Por acordo de arbitragem ou por contrato escrito; ou

iii) Por declaração num tribunal ou por comunicação escrita após o litígio entre as partes ter surgido"

b) O Estado reservou ou afectou bens para satisfação do pedido que constitui o objecto desse processo; ou

c) For demonstrado que os bens são especificamente utilizados ou destinados a ser utilizados pelo Estado com outra finalidade que não a do serviço público sem fins comerciais e estão situados no território do Estado do foro, com a condição de que as medidas de execução posteriores ao julgamento sejam tomadas apenas contra os bens relacionados com a entidade contra a qual o processo judicial foi instaurado (grifo nosso) $)^{10}$

Vale ressaltar que tal Convenção, assinada em Nova Iorque em 2 de dezembro de 2004, ainda não entrou em vigor no âmbito internacional, uma vez que encontra-se condicionada ao depósito do trigésimo instrumento de ratificação e até o presente momento apenas dezoito países confirmaram seu consentimento em fazer parte da mesma ${ }^{11}$.

Ainda assim, a corte francesa, enxergou neste instrumento, que havia sido ratificado pela França pouco mais de um mês antes da decisão, a manifestação de um costume internacional de que existem bens invioláveis para os quais uma renúncia expressa, e não em termos gerais, seria necessária. Diante disso, prevaleceu o entendimento de que quando um Estado renuncia sua imunidade sem fazer alusão a tal categoria específica de bens, esta renúncia atinge somente os bens que não são gravados de inviolabilidade, como por exemplo os bens ligados a uma atividade comercial.

\subsection{A análise dos tribunais ingleses acerca da imunidade de execução do}

${ }^{10}$ Versão autêntica do texto em português retirado do site do Departamento de Relações Exteriores de Portugal: http://dre.pt/pdf1s/2006/06/117A00/43444363.pdf..

${ }^{11}$ Os países que já ratificaram a presente Convenção são a Arábia Saudita, a Áustria, o Cazaquistão, a Espanha, a Finlândia, a França, o Irã, a Itália, o Japão, a Letônia, o Líbano, o Liechtenstein, a Noruega, Portugal, República Checa, Romênia, a Suécia e a Suíça. O Brasil nem mesmo assinou tal instrumento.

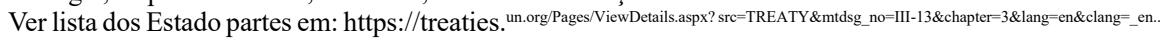




\section{Estado argentino}

Mesmo sendo o Reino Unido signatário da Convenção das Nações Unidas sobre Imunidades dos Estados e de seus bens - não tendo, contudo, até o presente momento, apresentado a sua ratificação - os tribunais britânicos não seguiram as suas disposições no que concerne a imunidade de execução dos Estados estrangeiros.

No julgamento NML Capital Limited v. Republic of Argentina, a Suprema Corte do Reino Unido entendeu que a cláusula que previa que o julgamento de um procedimento ligado a um litígio comercial era final e obrigatório, podendo ser executado diante de todo tribunal designado ou de qualquer outro que tenha competência, constituía um reconhecimento das jurisdições inglesas para o processo de execução.

Segundo Lord Phillips, que acompanhou o entendimento do juiz de primeira instância Blair, tal cláusula fazia prova de um acordo inequívoco sobre a possibilidade de execução dos julgamentos de Nova York diante de jurisdições mais adequadas ${ }^{12}$. Além disso, ele faz uma interessante consideração: sob o seu ponto de vista, obter o reconhecimento da sentença proferida em Nova York não é nada mais que uma etapa essencial para a sua execução.

Ao fazer uma interpretação teleológica de tal consideração, percebemos que o magistrado vinculou a renúncia da imunidade de jurisdição à renúncia da imunidade de execução.

Diante disso, Forteau (2012) faz um paralelo entre a abordagem de Lord Phillips no caso em tela com a solução adotada pela Corte de Cassação da França no caso Creighton ${ }^{13}$, onde ficou disposto que a adesão à um regulamento de arbitragem constitui além de uma renúncia à imunidade de jurisdição, uma renúncia à imunidade de execução do Estado estrangeiro. A jurisprudência francesa, no caso em questão, preferiu garantir a eficácia da arbitragem comercial internacional e assegurar a igualdade das partes no processo arbitral, inclusive no que concerne o cumprimento da sentença (FORTEAU, 2012).

Alguns veem nesta decisão um meio de dar segurança às trocas econômicas e de moralizá-las, garantindo, sobretudo, o respeito da boa fé contratual (ROMERO, 2002, p. 48). Com isso, o fundamento político das

${ }^{12}$ Suprema Corte do Reino Unido. NML Capital Limited v. Republic of Argentina, [2011] UKSC 31). Decisão de 6 de julho de 2011, §58.

${ }^{13}$ Corte de Cassação Francesa. Primeira Câmara Civil. État du Qatar c. Sté Creighton. Decisão de 6 de julho de 2000, comentário de J. Moury. 
imunidades aos poucos se curvaria diante de uma exigência moral: uma vez que o Estado se submete ao direito comum do comércio internacional, não é possível que ele possa romper a igualdade contratual resguardando-se atrás de privilégios exorbitantes quando vier a ser condenado em um procedimento de arbitragem regular, no curso da qual ele pôde se valer de todos os meios de defesa (OPPETIT, 1990, p. 62). Isso significaria, em última instância, aceitar uma forma de preclusão com base em uma renúncia implícita em nome de um dos pilares do Estado de Direito, que é a efetividade das decisões dos tribunais.

A Convenção das Nações Unidas sobre a Imunidade de Jurisdição dos Estados Estrangeiros e de seus bens dispõe, todavia, em sentido contrário. À luz de seu artigo 20:

Nos casos em que o consentimento para a adopção de medidas cautelares e de execução seja necessário em virtude dos artigos 18 e 19, o consentimento para o exercício da jurisdição ao abrigo do artigo 7 , não implica que haja consentimento para a adopção de medidas cautelares e de execução ${ }^{14}$.

Assim, sob a perspectiva do direito internacional recentemente codificado, o reconhecimento do valor obrigatório de uma decisão proferida por uma jurisdição e da obrigação de executá-la não se confunde com a autorização dada aos órgãos internos estatais de proceder à execução dos bens de um Estado estrangeiro. A razão de ser de tal distinção reside na qualidade particular do sujeito de direito em questão, qual seja, ser ele dotado de soberania (POIRAT, 2004, p. 42).

Assim, com a futura ratificação e entrada em vigor da Convenção das Nações Unidas sobre Imunidades Jurisdicionais dos Estados e dos seus bens, tal solução dos tribunais britânicos, que permite uma renúncia tácita à imunidade de execução, deverá ser sensivelmente modificada sob pena de ser incompatível com os artigos 18 e 19 do tratado em questão.

\subsection{A análise dos tribunais norte-americanos acerca da imunidade de execução do Estado argentino}

Conforme já exposto, no contexto atual, caso tais decisões contra o

\footnotetext{
${ }^{14}$ Versão autêntica do texto em português retirado do site do Departamento de Relações Exteriores de Portugal: http://dre.pt/pdf1s/2006/06/117A00/43444363.pdf.
} 
Estado argentino venham a ser executadas em solo norte-americano, os ditames da Convenção das Nações Unidas sobre a matéria não serão considerados uma vez que além dos Estados Unidos não serem signatários de tal texto, o mesmo ainda não se encontra em vigor no âmbito internacional.

No território estadunidense as regras que regulam a questão estão contidas no texto do Foreign Sovereign Immunities Act, que reconhece que os bens dos Estados estrangeiros, incluindo contas bancárias, gozam de imunidade de execução, salvo se tiverem destinação comercial.

Sob essa perspectiva, não haveriam razões para a Corte Internacional de Justiça, sendo competente, condenar os Estados Unidos pelo desrespeito do direito internacional das imunidades. O grande vilão da questão é certamente a interpretação controversa da cláusula pari passu que impediu a Argentina de honrar seus compromissos renegociados em 2005 e 2010. Tecnicamente falando, ao fazer valer uma decisão judicial irresponsável que impõe medidas econômicas privilegiando um grupo minúsculo de especuladores em detrimento de um processo negociado durante anos entre um Estado soberano e noventa por cento dos credores que vinha funcionando bem, os Estados Unidos não estariam violando o direito de imunidade argentino, mas a própria soberania deste Estado (SCHUTTE, 2014).

Ocorre que a Argentina recusou-se a efetuar o pagamento dos "fundos abutres" até 31 de dezembro de 2014, data em que a cláusula pari passu deixou de vigorar. Assim sendo, a Suprema Corte dos Estados Unidos determinou em uma decisão recente que a Argentina revelasse sua lista de ativos financeiros tanto nos Estados Unidos quanto no exterior, entendendo que o Foreign Sovereign Immunities Act apesar de impedir a penhora e a execução dos bens do Estado estrangeiro, não proíbe a imposição por um tribunal da divulgação de ativos extraterritoriais de um país estrangeiro. Diante disso, a discussão sobre a imunidade de execução dos bens do Estado estrangeiro voltou a figurar na pauta do dia...

\section{CONSIDERAÇÕES FINAIS}

Ao analisar as imunidades do Estado argentino, percebemos que apesar da sua imunidade de jurisdição não ter prevalecido perante a jurisdição norteamericana nem perante os tribunais arbitrais do ICSID, a discussão acerca dos limites de sua imunidade de execução foi alvo de interpretações diversas diante dos tribunais internos dos países que dispuseram sobre a questão. 
Enquanto Estados Unidos e França adotam uma posição bastante protetora do patrimônio estatal estrangeiro, o Reino Unido mostrou-se mais aberto à flexibilização das imunidades de execução dos bens argentinos situados em seu território.

O posicionamento da jurisdição francesa encontra amparo na Convenção das Nações Unidas sobre a Imunidade de Jurisdição dos Estados Estrangeiros e de seus bens, que apesar de ainda não ter entrado em vigor no âmbito internacional, foi considerada como sendo a manifestação do entendimento costumeiro acerca da matéria. Já para os Estados Unidos, foram as disposições do Foreign Sovereign Immunities Act que motivaram o entendimento dos tribunais internos, disposições estas que são também compatíveis com os termos Convenção.

Na contramão desse raciocínio encontram-se os tribunais britânicos, para os quais a cláusula que prevê a renúncia da imunidade de execução do patrimônio estatal pode ser geral, alcançando, inclusive, os bens deste Estado que se encontrem nos demais países do mundo.

Por um lado entendemos que possa ser difícil compreender quais razões fazem um tribunal estar convencido de que um Estado, que não é uma parte hipossuficiente na relação, mas que, ao contrário, também possui poder de barganha, não possa estar inteiramente vinculado por uma cláusula que ele próprio consentiu no curso das negociações, ainda que tal cláusula tenha caráter geral. Contudo, caso o Reino Unido venha a ratificar a Convenção das Nações Unidas sobre a Imunidade de Jurisdição dos Estados Estrangeiros, os tribunais britânicos deverão conformar tal interpretação aos ditames deste instrumento quando da sua entrada em vigor no plano internacional, prezando por uma renúncia específica para que um bem estatal com destinação pública possa ser executado em solo estrangeiro.

Por fim, constatamos que a cautela da Convenção das Nações Unidas sobre a Imunidade de Jurisdição dos Estados Estrangeiros age em favor do Estado argentino. Visando garantir o objetivo precípuo do direito das imunidades, qual seja, a proteção e manutenção das relações interestatais, esse tratado elimina o risco de um Estado ter seus bens destinados ao cumprimento de uma finalidade pública executados em solo estrangeiro sem que essa tenha sido sua real intenção. Apesar de ainda não ter entrado em vigor, a Argentina pode valer-se da viés costumeira deste texto para fundamentar, frente às jurisdições estrangeiras, o direito à imunidade de execução de seus bens que se encontrem fora do seu território. 


\section{REFERENCIAS}

BROWNLIE, Ian. Principles of public international law. 7. ed. Oxford: Oxford University Press, 2008.

DONOVAN, Donald Francis. Abaclat and others v Argentine Republic: As a Collective Claims Proceeding. ICSID Review, Oxford, v. 27, n. 2, p. 261-267, 2012.

FORTEAU, Mathias. La pratique des immunités des États étrangers en droits britannique et français: commentaire de l'arrêt NML Capital Limited (Appellant) v. Republic of Argentina (Respondent,) [2011] UKSC 31. 2012. Disponível em: <http://m2bde.u-paris10.fr/node/2392>. Acesso em: 16 out. 2014.

GAILLARD, Emmanuel. L'arbitrage sur le fondement des traités de protection des investissements. Revue de l'arbitrage, Paris, p. 853-875, 2003.

MADRUGA FILHO, Antenor Pereira. A renúncia à imunidade de jurisdição pelo estado brasileiro e o novo direito da imunidade de jurisdição. Rio de Janeiro: Renovar, 2003.

OPPETIT, Bruno. La pratique française em matière d'immunité d'exécution. In: LABOUZ, Marie-Françoise. L'immunité d'exécution de l'État étranger. Paris: Cahiers du CEDIN, 1990. p. 62.

POIRAT, Florence. Les immunités des sujets du droit international. In: VERHOVEN, J. Le droit international des immunités: contestation ou consolidation? Bruxelles: Larcier, 2004. p. 11-60.

ROMERO, Eduardo S. L'Arbitrage de la chambre de commerce internationale et les contrats d'État, Bulletin CCI, Paris, v. 13, n. 1, 2002.

SCHUTTE, Giorgio Romano. Thomas Griesa, a Argentina e os interesses hegemônicos. 2014. Disponível em: <http:/www.cartacapital.com.br/ economia/thomas-griesa-a-argentina-e-os-interesses-hegemonicos-6878.html $>$. Acesso em: 16 out. 2014. 
SHIBATA, Ibrahim. Toward a greater depoliticization of investment disputes: the roles o ICSID and MIGA. In: LU, Kevin; VERHEYEN, Gero; PERERA, Srilal. Investing with confidence: understanding political risk management in the 21th century. Washington: The World Bank Group, 2009. p. 2-34.

VERHOEVEN, Joe. Droit international public. Bruxelles: Larcier, 2000.

VERHOVEN, Joe. Le droit international des immunités: contestation ou consolidation? Bruxelles: Larcier, 2004.

Como citar: CAETANO, Fernanda Araújo Kallás e; WANDERLEY JÚNIOR, Bruno. A reestruturação da dívida pública argentina face ao direito de imunidade do estado estrangeiro. Scientia Iuris, Londrina, v. 20, n. 1, p.42-58 abr. 2016. DOI: $10.5433 / 2178-8189.2016 v 20 n 1 p 42$. ISSN: $2178-8189$.

Submetido em 18/10/2014

Aprovado em 23/07/2015 